\title{
Soil Resources and the Role in Agriculture Sector of Greek Economy
}

\author{
Paschalidis Ch. ${ }^{1, *}$, Sotiropoulos S. ${ }^{1}$, Papakonstantinou L. ${ }^{2}$, Petropoulos D. ${ }^{3}$, Kavvadias V. ${ }^{4}$, \\ Paschalidis D. ${ }^{5}$, Christodoulou Ch. ${ }^{6}$ \\ ${ }^{1}$ Department of Agriculture, University of the Peloponnes, Greece \\ ${ }^{2}$ Engineering Agronomist Freelancer, Greece \\ ${ }^{3}$ Department of Agriculture, School of Agriculture and Food Science, University of the Peloponnes, Greece \\ ${ }^{4}$ Department of Soil Science of Athens, Institute of Soil and Water Resources, Hellenic Agricultural Organization-DEMETER, Greece \\ ${ }^{5}$ CGK Consulting Ltd, Maroussi, Greece \\ ${ }^{6}$ Hellenic Ministry of Rural Development and Food, Greece
}

Received February 2, 2020; Revised April 22, 2020; Accepted May 13, 2020

Copyright $(2020$ by authors, all rights reserved. Authors agree that this article remains permanently open access under the terms of the Creative Commons Attribution License 4.0 International License

\begin{abstract}
This paper analyzes the quality of the soil resources of arable lands of the Hellenic Republic. Greece is characterized by mild winters and high sunshine. Greece's agricultural potential is hampered by poor soil conditions, inadequate levels of precipitation in spite of having also fertile soils and important water resources, especially in Western Greece. The mild climate allows Greece, especially in its southern regions, to produce early fruit and vegetable products. Data on the presence of saline, acid, and calcareous lands and the reasons for their formation in the country are presented. It refers to the basic characteristics of pathogenic soils, which have been studied in detail in recent years, their origin and their classification into several categories. Particular attention is paid to the serious problem of erosion and desertification of soil resources in many areas of Greece. It describes the important role that agricultural production has always played in the Greek economy. It is referred to the extent of cooperative organization which stays at low comparative levels, despite the efforts mainly of European Union. The total value of agricultural production in Greece amounts to 9.95 billion euros. Of this total, $69 \%$ comes from crop production. Consequently, crop production has a dominant position in the country's agricultural economy. Greek agriculture has remained at about the same level in terms of the value of agricultural production since 2010. As a percentage of the EU as a whole, however, it has dropped from $2.9 \%$ to $2.5 \%$. It also describes the agricultural economy and policy of the country, the prospects and the economic impact of the increase in the problematic agricultural lands. Some suggestions on measures to preserve national wealth, such as the country's land resources, are indicated.
\end{abstract}

Keywords Greek Agriculture, Soil Resources, Problematic Soils

\section{Introduction}

An increase in world population over the past forty years, an increase in the consumption of meat and dairy products in emerging economies, and a wider use of biomass for energy and other industrial purposes have led to an increase in the use of land resources in the world and potential soil degradation. To achieve this, productive land was needed for growing crops and natural vegetation. Unfortunately, however, a significant part of the soils, the so-called problem soils cannot be used for agricultural purposes. They always occur naturally, including saline soils, acid sulfate soils, sandy soils, skeletal soils and shallow soils. These soils are the source of serious soil degradation conditions that can accelerate the soil erosion process (FAO, 1994). At the same time, extreme weather events related to climate change, desertification and land occupation for urban expansion and construction of buildings exacerbate this trend (Lareshin et al., 2008). This is of direct interest in Greece and for Europe, as competition for land and water creates a serious threat of geopolitical imbalance. In addition, land degradation leads to a global reduction in multifunctional soils. In the future, the European Union will continue to depend on its limited land resources, including some of the most fertile soils in the world. The article provides data derived from recent soil surveys across main agricultural regions of Greece. The data related to land use for agricultural production, to 
the presence of problem soils, to soil degradation desertification, and erosion, in anticipation of their relative improvement.

\section{Distribution of Agricultural Land, Crop Production}

Greece's agricultural potential is hampered by poor soil conditions, inadequate levels of precipitation and a landholding system that has served to increase the number of unproductive smallholdings. In addition, the extent of cooperative organization stays at low comparative levels, against all efforts that have been taken in the last 30 years, mainly under European Union supervision. All of the aforementioned negatively affect agricultural production.

Nevertheless, agricultural production has always played an important role in the Greek economy. Important was the production of cotton, tobacco, etc. Greece has an important tradition in exporting agricultural products. It has to increase its competitiveness in the global economy. The majority of the rural population is engaged in agricultural production.

However, in recent years, agricultural production has reduced its contribution to the country's GDP, as the number of people involved has decreased. The area of our national space where dynamic farming can be developed, according to current data, occupies the plain and relatively smooth (hilly) areas where the most well-organized and sustainable farms are developed as they find the most application of modern technologies and improvement programs are more widely developed. The total value of agricultural production in Greece amounts to 9.95 billion euros. Of this total, $69 \%$ comes from crop production. Consequently, crop production has a dominant position in the country's agricultural economy. Greek agriculture has remained at about the same level in terms of the value of agricultural production since 2010. As a percentage of the $\mathrm{EU}$ as a whole, however, it has dropped from $2.9 \%$ to $2.5 \%$. As for crop production used as animal feed in livestock production, feed costs are among the highest in the EU (2nd) and tend to increase (from $63.6 \%$ in 2010 to $76.7 \%$ in 2014) In terms of employment, the share of the economically active population in the rural economy is about 13\% (13.5\% in 2014) (Savvas D., 2014; Paschalidis Ch et.al., 2018). Today more than $1,109,700$ million people are employed in agricultural production Gross value added at producer prices in crop production decreased from 5,410 $€ /$ ha in 2010 to $4,985 €$ / ha in 2014 . On the other hand, agricultural employment indices do not decline. Prices of vegetable and animal products from 2010 to 2014 remained stable. Greece, in general, imports more agricultural products than it exports, resulting in a negative balance. However, especially in the fruit and vegetable sector, exports are clearly outperforming imports. In 2018, exports of agricultural and processed agricultural products reached 5.9 billion euros, while imports reached 6.558 billion euros.
The trade balance of agricultural and processed agricultural products was negative and reached 657 million euros.

It is noted that the contribution of vegetables to total fruit and vegetable exports is relatively lower than that of fruits and amounted to 140 million euros in the years 2009-2013 (Savvas D., 2014, Piraeus Bank, 2020). The contribution of vegetables to total fruit and vegetable exports is relatively lower than that of fruit and amounted to $140,000,000$ euros in 2009-2013. Greece is characterized by mild winters and high sunshine, while it has fertile soils and significant water resources, especially in western Greece, which is considered a climate-favored site for crop production. The mild climate allows Greece, especially in its southern districts, to produce early fruit and vegetable products, that is, products produced earlier than usual in other parts of the country and in other countries. According to the Ministry of Environment and Physical Planning 2014, 54.6\% of the total area under cultivation is used for annual arable crops, $2.8 \%$ for vegetable crops, $32 \%$ for permanent crops (mainly tree crops), while $10.6 \%$ corresponds to in fallows. Greece is one of the few European Union (EU) countries with a high percentage of tree crops in all cultivated areas. In the period 2000-2010, agricultural land in Greece accounted for $66 \%$ of the total land area, covering an area of 8,700 hectares. Forest area amounted to $28 \%$, that is, 3.700 hectares out of a total of 13,300 hectares (table 1).

In addition, $56 \%$ of arable land is in lowland (plain) areas, and the rest is in mountainous or semi-mountainous areas. Finally, $82.7 \%$ of agricultural land is used in less favorable areas, of which $56.4 \%$ are in mountainous areas. The corresponding figures for the EU-25 are $55.4 \%$ and $16.3 \%$.

From the lands used for agricultural production, 3,300 ha are cultivated by agricultural crops, and 490,000 ha are pastures. Approximately 500,000 ha arable land is allocated annually, while one third of the arable land is irrigated. Although the area of arable land remains almost unchanged, irrigated land has almost tripled (Table 2). (Kaditi E. et.al., 2010).

Factors such as morphology and the lack of adequate spatial organization of land use, as well as the preservation of traditional administrative models (heritage and property) have led to small scattered plots of land. The lack of transfer or consolidation of agricultural land in Greece is due mainly to the aging population of the Greek countryside. Moreover, as the number of people employed in the agricultural sector decreases, the number of farms does not decrease at the same time, so that the remaining agricultural farmers can increase their farm areas.

It is worth noting that the area of cultivated land in Greece decreased due to a decrease in the production of cotton and tobacco, as well as grain and oilseeds. Currently, the most important crops in terms of area are cereals, fruit plantations and industrial crops. With regard to the specialization of crops, in 2015 , approximately $22 \%$ were mixed crops, and $78 \%$ were specialized. 
Table 1. Land distribution in Greece (\%)

\begin{tabular}{|c|c|c|c|c|c|}
\hline & $1960-1969$ & $1970-1979$ & $1980-1989$ & $1990-1999$ & $2000-2010$ \\
\hline Agricultural land (\% of land) & 70 & 71 & 71 & 70 & 66 \\
\hline Cultivated land (\% of land) & 23 & 23 & 22 & 22 & 21 \\
\hline Forest land (\% of land) & - & - & - & 26 & 28 \\
\hline
\end{tabular}

Source: Kaditi E and Nitzi E., 2010

Table 2. Agricultural land in Greece (thousand ha)

\begin{tabular}{|c|c|c|c|c|c|c|c|c|c|}
\hline Area & $\begin{array}{c}1961- \\
1965\end{array}$ & $\begin{array}{c}1966- \\
1970\end{array}$ & $\begin{array}{c}1971- \\
1975\end{array}$ & $\begin{array}{c}1976- \\
1980\end{array}$ & $\begin{array}{c}1981- \\
1985\end{array}$ & $\begin{array}{c}1986- \\
1990\end{array}$ & $\begin{array}{c}1991- \\
1995\end{array}$ & $\begin{array}{c}1996- \\
2000\end{array}$ & $\begin{array}{c}2001- \\
2003\end{array}$ \\
\hline $\begin{array}{c}\text { Average } \\
\text { area }\end{array}$ & 8.900 & 9.129 & 9.143 & 9.153 & 9.197 & 9.195 & 9.165 & 8.828 & 8.460 \\
\hline $\begin{array}{c}\text { Irrigated } \\
\text { lands }\end{array}$ & 530 & 677 & 835 & 941 & 1.021 & 1.177 & 1.311 & 1.442 & 1.438 \\
\hline $\begin{array}{c}\text { Cultivated } \\
\text { land }\end{array}$ & 3.800 & 3.889 & 3.894 & 3.898 & 3.942 & 3.940 & 3.926 & 3.878 & 3.843 \\
\hline
\end{tabular}

Source: Kaditi E and Nitzi E., 2010.

Table 3. Distribution of soils depending on the slope and altitude

\begin{tabular}{|c|c|c|c|}
\hline Slope $\%$ & Total agricultural land $\%$ & Altitude, $\mathrm{m}$ & Total agricultural land \% \\
\hline $0-5$ & 35.8 & $0-400$ & 51.3 \\
\hline $5-10$ & 15.3 & $400-800$ & 20.1 \\
\hline $10-15$ & 48.9 & $>800$ & 28.6 \\
\hline
\end{tabular}

Source: Simonis A., 1993

Table 4. Classification of soil quality in Greece

\begin{tabular}{|c|c|c|}
\hline Soil category & $10^{3}$ ha & $\%$ \\
\hline High soil quality & 2,492 & 19 \\
\hline Average soil quality & 2,334 & 18 \\
\hline Poor soil quality & 7,578 & 57 \\
\hline Area not included (urban land, lakes, missing data) & 790 & 6 \\
\hline
\end{tabular}

Source: CEC 1992

The soil resources of Greece are among the most vulnerable to degradation, since soil, geological, topographic and climatic conditions are unfavorable. The relatively low percentage (1-1.5\%) of soil organic matter content, the intense terrain with fragile geological materials covering most of the surface, mountain ranges and strong slopes of the earth contribute to soil degradation (Table 3). (Simonis A, 1993).

Agricultural land has the highest productivity for the use of certain goals, without loss of productivity. Pastures land have medium productivity and forests land have even lower productivity. High-quality soils occupy $2,492,000$ ha, soils of average productivity occupy 2,334,000 ha, and poor-quality soils occupy $7,580,000$ ha (Table 4 ).

\section{Problem Soils}

It is well known that soil formation is determined by the influence and interaction of various factors, such as source material (parent rock), climate, fauna and flora, topography, time and anthropogenic impact. Soils acquire various properties (natural chemical and biological) that are directly related to their use for a specific purpose. Nevertheless, there are some groups of soils with certain properties, which in fact create unfavorable conditions for plant growth, which makes them prohibitive for any cultivation.

In these cases, the problem soil is determined solely on the basis of their specific features, that is, either a very acidic $\mathrm{pH}$, or an extremely high salinity, or a high content of $\mathrm{CaCO}_{3}$. In this sense, the soil is actually problematic, because it is unsuitable for any use under agricultural crops. These lands must be improved in order to be used.

Problem soils, according to the FAO reference, are classified into the following categories

a) Salt affected soils b) Acid soils c) Calcareous d) Organic or peat soils e) Heavy clay soils and f) Steep slope soils

In Greece arid conditions prevail, contributing to the formation of especially saline soils, which contributes to the presence of problematic soils. The main anions that cause mineralization of the soil are chlorine, sulfate, sodium and magnesium, and sometimes nitrates. The main 
features of pathogenic soils were studied in detail in the period 1969-1990, and their origin was studied in the soil-climatic conditions of the country. It was found that the categories of pathogenic soils are as follows: a) saline soils ( $\mathrm{pH}<8.5, \mathrm{EC}<4 \mathrm{dS} / \mathrm{m}, \mathrm{ESP}>15 \%)$, b) alkaline soils $(\mathrm{pH}>8.5, \mathrm{EC}<4 \mathrm{dS} / \mathrm{m}, \mathrm{ESP}>15 \%)$ and $\mathrm{c})$ saline - alkaline $(\mathrm{pH}<8.5, \mathrm{EC}>4 \mathrm{dS} / \mathrm{m})$. The factors contributing to the emergence of pathogenic soils are: (a) source material, (b) high groundwater level (c) seawater, and use of brackish water, (d) insufficient soil drainage and (f) dry climate conditions and salts accumulation occurs due to poor drainage particularly in the regions of Karditsa (Central Greece), and Vromolimnon-Thessaloniki (North Greece). It can be seen that a greater number of saline soils $(10,400$ ha) are in the Xanthi region, Northeastern Greece, and 6,355 ha are alkaline-alkaline soils in the region of Etoloacarnania, West Greece. The area of pathogenic soils according to categories is as follows: alkaline soils make up 34,916 ha, saline soils 35,389 ha, alkaline soils 17,818 ha and a total of 88,123 ha. It is a fact that the use of irrigation water, which can be saline, is one of the main reasons for the formation of saline and alkaline soils. These poor-quality irrigation waters create the so-called secondary salinity of soils in many regions of the country. There is a specific case of secondary salinization of the soil with sea water that has penetrated the depths of the mainland, where there are citrus plantations, in the Nafplio province the Argolida region, Peloponnese, South Greece.

It should be noted that there are acidic soils that are used in agricultural production. Acidic soils are classified into the following categories: (a) partially acidic $\mathrm{pH}$ 6.5-5.5, and (b) strongly acidic $\mathrm{pH}$ below 5.5-3.5. Acidic soils are formed like all soils under the influence of climate factors, topography, vegetation, source parent material and time. Acidic soils are considered problematic due to their low $\mathrm{pH}$ Often, high acidity creates extremely unfavorable conditions for plant growth. This has important implications for agricultural production and the economy as a whole. It is estimated that $15 \%$ of Greek soil has an acid $\mathrm{pH}$. In Greece, acidic soils are found in mountainous regions (at an altitude of more than 1000 meters) at a semi-mountain height below $<1000-600$ meters, and in lowlands. Factors contributing to the formation of acidic soils are acidic parent geological rocks consisting of natural granite, slates and phyllites (Koroxenidis, 1985).

The fact that there are acidic soils in the mountainous regions of the country in addition to the presence of acidic rocks depends on a large amount of precipitation, as well as a small amount of evaporation. These conditions contribute to the leaching of bases and ultimately lead to soil acidification. Acidic mountainous and semi-mountainous soils from a mechanical point of view, for the most part is SL to LS, that means a light mechanical composition promoting leaching.

Regarding soils in areas of low hills, despite the low rainfall prevailing in the respective areas, however, many of these soils have a pH below 5.5, that is, they are acidic. This fact is explained by the following: (a) that acid nitrogen fertilizers (ammonium sulfate) have been used for many years, (b) large doses of nitrogen, and (c) monoculture of wheat cultivated for many years. The $\mathrm{pH}$ of the acidic soils of Greece ranges from 5.5-4.8 and may be 4.3-4.4.

Unfortunately, there are no statistics on the extent of acid soil areas by region for all of Greece. However, there is relevant area information and an estimate of the extent of acid soils in Northern Greece which are given in table 5.

Table 5. Acidic soil areas in regions of Northern Greece

\begin{tabular}{|c|c|c|c|}
\hline Region & Area (ha) & Region & Area, (ha) \\
\hline Thessaloniki & 18,000 & Castorias & 10,000 \\
\hline Halkidiki & 12,000 & Florinas & 6,000 \\
\hline Kilkis & 50,000 & Cavalas & 3,000 \\
\hline Imathias & 2,500 & Dramas & 7,000 \\
\hline Pellas & 4,000 & Serron & 1,600 \\
\hline Pierias & 3,000 & Xanthis & 9,000 \\
\hline Kozanis & 3,500 & Rodopis & 7,000 \\
\hline Grevenon & 5,000 & Evros & 12,000 \\
\hline
\end{tabular}

Source: Koroxenidis, 1987

The data in table 5 show that in Kilkis there are the most areas of acidic soils, follow the region of Thessaloniki and the total area of acidic soils in Northern Greece is 153,600 ha. The $\mathrm{pH}$ of these acidic soils is below 5.5. These are mainly red lands (SCL) on the old plains and low hills, where annual crops are mainly grown. These soils can also be found on recent alluvial deposits (LS and SL) (Koroxenidis, 1987). In Greece there are calcareous soils characterized by the presence of calcium carbonate from $20 \%$ to $80 \%$, which makes them problematic for the crop production development .These soils are usually formed under the influence of a dry thermal climate, which does not contribute to the leaching of carbonates and, consequently, to their accumulation in its horizons and calcareous soils arise (Ruellan, 1977). Due to good coagulation, accumulation and binding, they have the desired structure and, therefore, have satisfactory filtering. However, the fertility of these soils has significant problems with the availability of nutrients due to the high $\mathrm{pH}>7.0-8.3$. The calcareous soils in Greece are usually poor in organic matter and available nitrogen, and also because of their high $\mathrm{pH}$, they are usually not adequately supplied with some macronutrients, such as mobile phosphorus, due to its binding, and available microelements, such as zinc, manganese, iron, the binding of which can sometimes approach 70 to $80 \%$. In particular, the problem of iron chlorosis manifests itself very sharply, especially on citrus and grape plantations that suffer from serious symptoms of iron deficiency when growing them on calcareous soils. Often phosphorus deficiency also occurs due to its fixation, which reaches up to $60-80 \%$ of 
doses of phosphorus fertilizer. Despite these problems that exist in calcareous soils, productivity is significantly improved when they are irrigated and a rational agricultural system is introduced. (Koukoulakis \& Papadopoulos, 2007). Greece, in addition to problem salted acidic calcareous soils, there are two other main problems associated with soil, such as erosion and desertification of territories. Erosion causes soil degradation, partial or complete loss of productivity. The physical natural geological geomorphological topographic and climatic conditions of the country contribute to the development of all forms of erosion (Michios et. al., 1995). Greek soils are among the most sensitive to erosion in the world for the following reasons:

a) There is no formation of stable soil colloids that counteract the destructive power of rain drops.

b) Low soil water-absorbing ability

c) The fragile geological rocks and minerals that are found in most Greek lands

d) The surface of mountain ranges and sharp declines

e) The dry climate with a combination of heavy rains

In addition to the above reasons, there are other factors that cause soil erosion in Greece, such as the limited use of manure and other organic fertilizers (green fertilization with various plant residues, municipal wastewater, etc.), the use of heavy machinery, insufficient monoculture of the soil cover for many years, sowing of grain on mountainous areas, excessive grazing and frequent fires observed on pastures and forests. In Greece, about 26.5\% of the total land area $(3,500,000$ hectares approximately) are subject to various erosion. Even worse, with the problem of desertification of the lands in Greece, according to the National Committee for the study of the problem of desertification, $35 \%$ of the territory of Greece are at risk or already have signs of desertification, $49 \%$ are at moderate risk, and only $16 \%$ of the country is not at risk. $8 \%$ of agricultural land in Greece - about 300,000 ha essentially should be taken out of production, since they can no longer be cultivated. More sensitive areas of Greece include Crete, the Aegean, East Peloponnese, East-Central Greece, Evia, parts of Thessaly and specific areas of Macedonia and Thrace. The degradation of soils to such extent that they lose their fertility, "to die", are caused by various factors, including climate change and human activities. Thus, desert land is not capable of either producing or conserving vegetation. It takes 5-10 centuries in the case of limestone rocks and 50 years in the case of shale rocks to create one centimeter of soil. But it can be destroyed within a decade. Soil is a natural resource that can hardly be replaced (Kosmas, 2017). The lack of land use planning in Greece exacerbated the problem, because in areas such as Thessaly plain, where land was industrial enterprises were created, intensive cultivation on that plain led to the depletion of groundwater, resulting in salt water reaching the Karditsa plain of Thessaly nowadays. The risk of desertification is very high in Greece and the rest of area from the
Mediterranean basin. The areas most at risk of desertification are in North Africa, the Middle East and Europe. Especially for Europe, the most vulnerable areas outside Greece are Southern Italy, Sicily, Corsica and the Iberian Peninsula. According to the National Committee for the Study of Desertification, Turkey, Tunisia and Morocco lose thousands of acres of arable land each year due to erosion. In fact, climate change and rising temperatures create a vicious circle that dramatically affects development the phenomenon. Rising temperatures and heavy rains accelerate the desertification process. At the same time, when the soil is a dead body, it cannot only "nourish" plants that protect the erosion process, but also cannot control the temperature changes.

\section{Concluding Remarks}

Based on the analysis of the data on the situation of agricultural lands in Greece, conclusions and suggestions for their conservation can be drawn, which can be summarized below.

1. A more detailed overview of the quality of the soil resources of arable lands of the country.

2. It is necessary to constantly monitor the problematic soils of Greece and to develop and apply a national strategy for the protection of the country's land resources.

3. Technical measures in the field of agriculture, mainly related to the development of irrigation networks, desalination of soil and anti-erosion works.

4. Protection of forest vegetation, which is a universal necessity of the highest priority. A very cautious change in land use in forest lands. Taking measures to reduce forest fires.

5. Making a plan for the management and operation of pastures. Control of overgrazing and development of livestock on productive and corrosion-resistant areas.

6. Rational use, which is an essential prerequisite for their viability. Should be preferred forest exploitation in areas with steep slopes, pastures use in areas with moderate slopes, and agriculture use in flat or low-sloped areas.

7. Definition of national land policy, defining land use zones and basic tenure rules, ensuring its sustainability. Advisory measures for farmers on issues related to soil erosion, irrigation water, use of innovative technologies in the cultivation of agricultural crops.

\section{REFERENCES}

[1] CEC, 1992. The State of the Environment in the European Community, EEC Com (92) 23 final vol. III, Brussels, Belgium. 
[2] European Commission, 2007. Agriculture in the European Union, Statistics and Economic Information. DG for Agriculture and Rural Development Brussels.

[3] European Commissiion - Eurosttat, 2010. Farm Structure-Historical Results- Surveys from 1966/67 to 1997. Eurostat.

[4] FAO. 1994. The collection and analysis of land degradation data. RAPA Publication1994/3 Bangkok: FAO

[5] Kaditi E., Nitsi E., 2010. Agricultural Sector in Greece, Athens, p. 266. (In Greek).

[6] Koroxenidis N., 1985. Problems of acidic soils First Scientific Conference of the Greek Association of Soil Scientists, Thessaloniki pp. 101-106. (In Greek).

[7] Kosmas K., 2017. Desertification of the land - the experience of Greece Environment - Ecology. Athens, ((in Greek)

[8] Kosmas, C., N. Moustakas, N. Danalatos and N. Yassoglou.1996. The Spata field site in: J. Thornes and J. Brandt(eds), Mediterranean desertification and land use, J. Wiley and Sons, Chichester England, pp.207-228.

[9] Koukoulakis P., Papadopoulos A., 2007. Problematic soils and their improvement Publisher A., Stamulis, Athens, p. 401 (in Greek)

[10] Koukoulakis P., Simonis A., Herzis A., Paschalidis H., and Rigas G., 2000. Problem maps due to soil salinity and the basis for fertilizing. 8 Congress of the Greek Association of Soil Scientists. Kavala, pp. 178-189 (in Greek).

[11] Lareshin V., Bushuev N., Skorikov V., Shuravilin A., 2008. Preservation and increase of fertility of agricultural land. Textbook of RUDN University, Moscow

[12] MisopolinosN., 1991. Problematic Soils Studying Prevention Improvement Publishing House Yahudi-Yapudi Thessaloniki.

[13] Michios I., Paschalidis H., Paganias K., 1995. Soil erosion Anti-erosion protection measures Publisher ZYMEL Athens p. 68 (in Greek).
[14] Oldeman, L., 1994. The global extent of soil degradation. In D. Greenland, and I. Szabolcs (eds), soil resilience and sustainable land use $\mathrm{CAB}$ International, Wallingford, $\mathrm{pp}$. 99-118.

[15] Paganias K., Michios I., Paschalidis H., 1992. National Problem Protection from Soil Erosion of Greece J. Al Rural Copy of Athens pp. 5-8 (in Greek).

[16] Paschalidis Ch., Petropoulos D., Sotiropoulos D., L. Papakonstinou., 2018. The European Union S Common Agricultural Policy and Development of Agro- Food Sector in Greece. RUDN Journal of Agronomy and Animal Industries Vol.13N0 4 pp 373-382.

[17] Paschalidis Ch., Petropoulos D., Sotiropoulos S., Zamanidis P., Chamourliev G., L., Papakonstinou.2018. Human trends of Greece agricultural policy. Volgograd: VGAU Publ., 2018 .

[18] Paschalidis Ch., Sotiropoulos S., Kavvadias V., Chouliaras I., Theodorou M., Liakopoulou Ch and D., Petropoulos 2016. The Effect of Climate and Other Factors of Organic Matter in Greek Soil. Fourth National Conference Humus Substances and their Contribution to the Climate Change Mitigation Sofia Bulgaria page. 133-141.

[19] Piraeus Bank. 2020. ON EARTH. Edition for the rural economy. Issue 16. (In Greek).

[20] Ruellan, A., 1977. Morphology and Distribution of calcareous Soils in the Mediterranean and Desert Regions FAO Bull. 21. Calcoreous Soil. FAO Rome 1977.

[21] Savvas D.2014. Development of plant production in Greece. Athens. (In Greek).

[22] Simonis A., 1993. Problem soils of Greece FAO / ECE symposium on Agriculture and the Environment, Geneva Switzerland.

[23] Soil Survey Staff, 1975. Soil Taxonomy a basic system of soil classification for making and interpreting soil surveys USDA Agricultural Handbook 436.U.S Government Printing Office, Washington, D.C., p.754. 